\title{
Ionic Conductivity of Bulk, Gels and Solutions of Perfluorinated Ionomer Membranes
}

\author{
P. Aldebert, M. Guglielmi, and M. Pineri
}

\author{
Centre d'Etudes Nucléaires de Grenoble, DRF-G/Service de Physique, \\ Groupe Physico-Chimie Moléculaire, \\ $85 X$-3804I Grenoble Cedex, France
}

(Received November 29, 1990)

\begin{abstract}
Perfluorinated ionomer membranes either sulfonated or carboxylated have been extensively studied in order to understand the relations between their structure and properties. In addition to their uses as separator in the $\mathrm{Cl}_{2} / \mathrm{NaOH}$ industry large potential applications exist in different fields like sensors, batteries, fuel cells, electrochromic displays, etc. Some of these applications are due to the possibility of getting solutions, gels from these materials in different solvents and of reconstructing membranes of different thicknesses. The aim of this presentation is to present conductivity measurements of solutions, gels and bulk membranes, which measurements are of primary interest for potential applications in electrochemical
\end{abstract} devices.

Room temperature measurements of conductivity of solutions/gels: First of all we recall the results already published which show the high conductivity of these gels associated with a transport number $t^{+}=1$ since the $\mathrm{COO}^{-}$or $\mathrm{SO}_{3}^{-}$anions are covalently bound to the rigid perfluorinated rod like structure.

Low temperature measurements: Polymers having ionic conductivity usually show drastic changes upon temperature associated to transition $\left(T_{g}, T_{m}\right.$ or sub $T_{g}$ relaxations). Measurements of conductivity of NAFION ${ }^{(\mathbb{R})} 1100$ solutions in propylene carbonate or dimethoxyethane over a temperature range between $+20^{\circ} \mathrm{C}$ and $-40^{\circ} \mathrm{C}$ have shown only small changes mainly due to viscosity modifications of the solvent as evidenced from the calculated activation energies. Conductivity/swelling measurements: we have recently developed an experiment which permits to obtain both the conductivity and the swelling of ion exchange membranes. Equilibrium experiments with solvent mixtures permit to check the conductivity and swelling changes versus different parameters (dielectric constant of solvent, ionic radius of the counterion, etc.). Diffusion coefficients are also obtained from the time lag when immersing the membrane in the solvent.

KEY WORDS Perfluorinated Ionomer Membranes / Gelatinous Solutions / Conductive properties / Swelling / structure / 
Perfluorinated sulfonate ionomers (Nafion ${ }^{\mathbb{R}}$ products, E.I. Dupont de Nemours and Co) are used in a large variety of electrochemical and chemical applications. The largest application is separator in the $\mathrm{Cl}_{2}$ / $\mathrm{NaOH}$ industry by taking advantage of the membrane properties, i.e., its chemical resistance even in very corrosive media and moderate swelling in aqueous solutions, with both a good ionic conductivity and selectivity. Few years ago, the dissolution of the 1100 equivalent weight polymer $(.91 \mathrm{meq} / \mathrm{g})$ was achieved, $1-3$ and gels or solutions so obtained have opened a new attractive field of applications either as electrolyte in electrochemical devices or as starting material for composites. In addition, solution cast films can be obtained by evaporation of the solvent followed by thermal treatment. ${ }^{4}$

When equilibrated in ambient atmosphere, the membrane forms microdomains containing ions and sorbed water surrounded by the hydrophobic perfluorinated matrix. The low water content of the membrane results in a poor cationic conductivity which becomes high when the membrane is swollen by water or polar solvents. The cation versus the anion selectivity is related to the structure of the membrane. 5

A rod-like structure has been evidenced for the solutions by neutron scattering experiments, ${ }^{6}$ with an ionic conductivity which depends on the nature of the solvents, the concentration in polymer, the temperature and the water content. 7

The aim of this paper is to report conductance measurements of Nafion 1100 gels in propylene carbonate (PC) and in a 50/50 mixture by volume of propylene carbonate with dimethoxyethane (PC/DME). Measurements have been performed from $25^{\circ} \mathrm{C}$ to $-40^{\circ} \mathrm{C}$ because of the potential batteries applications. Also, in view of applications and for the understanding of the membrane conductive properties, we report kinetic measurements of the conductance performed upon the swelling on membranes exchanged by proton, lithium, sodium, and rubidium cations, from which ion diffusion coefficients have been calculated. The solvents used were water, ethanol (EtOH), n-methylformamide (NMF) and propylene carbonate.

\section{EXPERIMENTAL}

The general formula of Nafion ${ }^{(\mathbb{B})}$ membranes is :

$$
\begin{aligned}
& {\left[\left(\mathrm{CF}_{2} \mathrm{CF}_{2}\right)_{\mathrm{n}}-\mathrm{CF}_{2} \mathrm{CF}\right]_{\mathrm{x}}} \\
& \qquad\left[\mathrm{OCF}_{2} \mathrm{CF}\left(\mathrm{CF}_{3}\right)\right]_{\mathrm{m}} \mathrm{OCF}_{2} \mathrm{CF}_{2} \mathrm{SO}_{3} \mathrm{Li} \\
& \qquad\left\{\begin{array}{l}
m=1 \\
n \sim 6,4
\end{array}\right.
\end{aligned}
$$

and for $1100 \mathrm{EW}$ :

Solvents: The main solvent properties (dielectric constants $\varepsilon$, viscosity $\eta$, molar volume $v_{M}$, Gutmann donor number DN) which determine the electrolyte conductivity are summerized in table 1. 
Table 1. Solvents properties from "Ion solvation" by Y. Marcus Wiley, New York (1985). Values in parentheses have been obtained indirectly.

\begin{tabular}{|c|c|c|c|c|}
\hline solvent & $\epsilon$ & $\begin{array}{c}\eta \\
\left(10^{-3} \mathrm{~Pa} . \mathrm{s}\right)\end{array}$ & $\begin{array}{c}\mathrm{V}_{\mathrm{M}} \\
\left(\mathrm{cm}^{3} . \mathrm{mol}^{-1}\right)\end{array}$ & $\begin{array}{c}\mathrm{DN} \\
\left(\mathrm{kcal}^{\mathrm{mol}} \mathrm{mol}^{-1}\right)\end{array}$ \\
\hline $\mathrm{H}_{2} \mathrm{O}$ & 78.39 & .89 & 18.07 & $(18)$ \\
EtOH & 24.55 & 1.078 & 58.7 & $(32)$ \\
TEP & 13.3 & 1.55 & 170.3 & $(26)$ \\
NMF & 182.4 & 1.65 & 59.1 & $(25)$ \\
PC & 66.1 & 2.513 & 85.2 & 15.1 \\
Dioxane & 2.2 & 1.194 & 85.7 & 14.8 \\
Acetonitrile & 37.5 & .341 & 52.9 & 14.1 \\
Xylene & 2.27 & .605 & 123.9 & $(5)$ \\
Hexane & 2.023 & .299 & 131.6 & 0 \\
\hline
\end{tabular}

Gels: Dissolution of Nafion membrane was performed following the process already described in the literature. ${ }^{3}$ The polymer was dissolved at high temperature in a 50/50 (by volume) water/alcool mixture in an autoclave. ${ }^{3}$ The so-obtained solution was then evaporated leading to blocks which were dissolved in polar solvents, after cryocrushing and dehydration at $110^{\circ} \mathrm{C}$ under vacuum. Propylene carbonate and dimethoxyethane were distilled on sodium under reduced argon atmosphere. The water contents were measured by the Karl-Fischer method using a Tacussel aquaprocessor. The water concentration was $\sim 10^{-4} \mathrm{M}$ in the pure solvents and $\sim 10^{-3} \mathrm{M}$ in the polymer solutions. All samples were prepared and measurements performed in a glove-box under argon atmosphere. A laboratory built cell thermostat allowed samples regulation from $-45^{\circ}$ to $25^{\circ} \mathrm{C}$. Its calibration gave the samples temperature within $\pm 0.25^{\circ} \mathrm{C}$. Conductance measurements of gels were performed at $1000 \mathrm{~Hz}$, using a Tacussel platinum platinized electrode conductimeter.

Membranes: Commercial $175 \mu$ membranes were boiled in nitric acid, washed with distilled water, dried and kept under vacuum up to be used. Lithium, sodium, and rubidium exchanges were performed using chlorides. The membranes were then rinced with bidistillated water. The flatness was obtained by drying the membranes at $110^{\circ} \mathrm{C}$ under vacuum between two pieces of porous stainless steel. Figure 1 gives the scheme of the cell used to measure the conductance during the solvent uptake along the thickness. An Enertec CD8505/1 type displacement gauge, fixed on the top of the upper electrode, gave the thickness increase with an accuracy of $0.25 \mu$. In dynamic conditions data acquisition was performed by the soft Asystant via a multiplexed multimeter/convertissor Keithley 1992. An a.c. impedancemeter HP 4192A was used for steady state resistance measurements of membranes from 5 to $13 \mathrm{MHZ}$. 


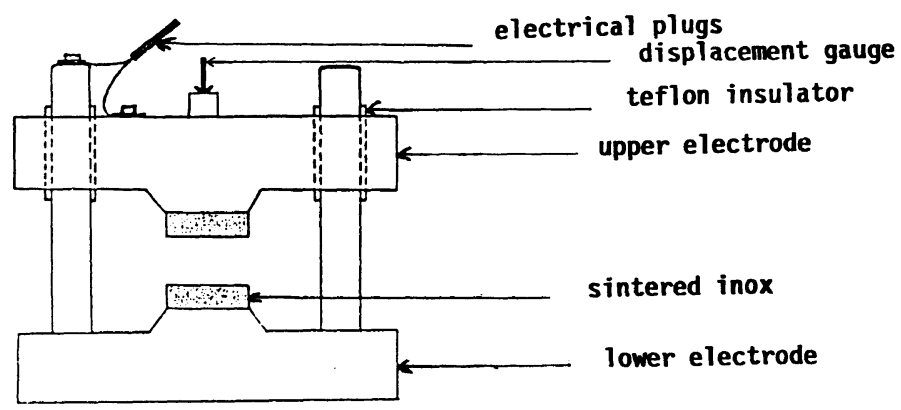

Figure 1. Scheme of the cell used for measurements of the conductance and the thickness variations during the swelling of Nafion membranes.

\section{RESULTS AND DISCUSSION}

Gels: Conductivities of gelatinous solutions in NMF, PC and TEP versus the concentration and the temperature $\left(20^{\circ} \mathrm{C}\right.$ to $\left.80^{\circ} \mathrm{C}\right)$ have been given in a previous paper. ${ }^{7}$ Figure 2 shows the variations of the conductivity with the concentration in PC and in a (50/50 by volume) mixture of $\mathrm{PC} / \mathrm{DME}$ at $-40^{\circ} \mathrm{C},-20^{\circ} \mathrm{C}, 0^{\circ} \mathrm{C}$, and $40^{\circ} \mathrm{C}$. The gel conductivity in the PC/DME mixture is twice that in pure PC, since DME is used as a low viscosity co-solvent.

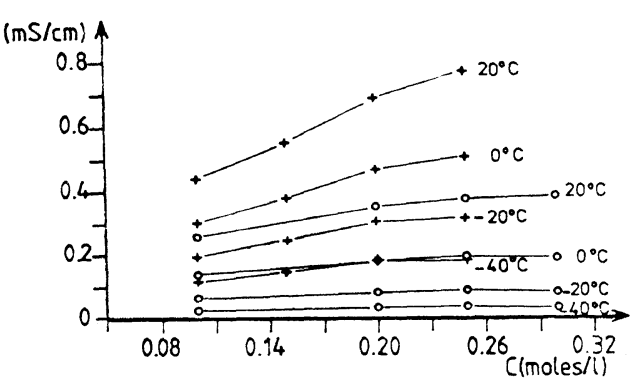

Figure 2. Conductivities versus the concentration of Nafion $\mathrm{Li}^{+}$ solutions in $\mathrm{PC}(\mathrm{O})$ and in a 50/50 mixture of PC/DME $(+)$.

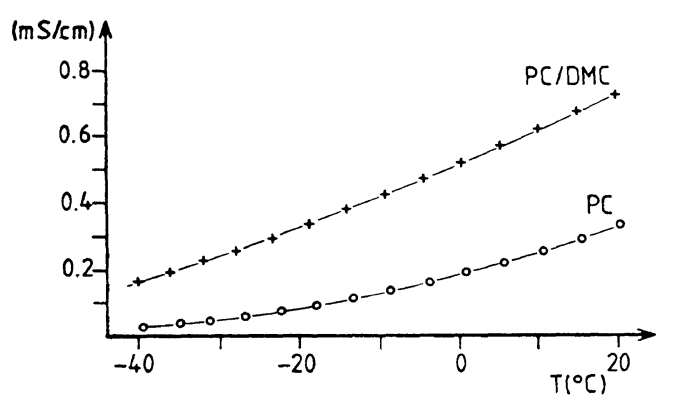

Figure 3. Conductivities of $.25 \mathrm{M}$ Nafion $\mathrm{Li}^{+}$solutions in $\mathrm{PC}$ and in a 50/50 mixture of $\mathrm{PC} / \mathrm{DME}$ from $-40^{\circ} \mathrm{C}$ to $20^{\circ} \mathrm{C}$.

Figure 3 gives the conductivities of $.25 \mathrm{M}$ solutions in $\mathrm{PC}$ and in a $(50 / 50)$ mixture of $\mathrm{PC} / \mathrm{DME}$ from $-40^{\circ} \mathrm{C}$ to $25^{\circ} \mathrm{C}$. The variation of the conductivity with temperature is continuous over the range $-40^{\circ} \mathrm{C}$ to $20^{\circ} \mathrm{C}$ (the $\mathrm{PC}$ and $\mathrm{PC} / \mathrm{DME}$ melting points are $-54.5^{\circ} \mathrm{C}$ and $-58^{\circ} \mathrm{C}$ respectively). Therefore there is no structural change in the ionic part of the polymer. Table 2 gives values of activation energies deduced from plots of the logarithm of the conductance versus $T^{-1}$ for 
Table 2. Activation energies values ( $\pm 2 \mathrm{kcal}_{\mathrm{mol}}{ }^{-1}$ ) for different concentrations of Nafion $\mathrm{Li}^{+}$gels in PC and PC/DME from $25^{\circ} \mathrm{C}$ to $-40^{\circ} \mathrm{C}$.

PC $\quad P C / D M E$

\begin{tabular}{|c|c|}
\hline $\begin{array}{c}C \\
(M)\end{array}$ & $\begin{array}{c}\text { Ea } \\
\left(\mathrm{kcal} . \mathrm{mol}^{-1}\right)\end{array}$ \\
\hline .10 & 2.2 \\
.21 & 2.3 \\
.25 & 2.3 \\
.37 & 2.5 \\
\hline
\end{tabular}

some concentrations of the polymer in PC and PC/DME solutions in the range $-40^{\circ} \mathrm{C}$ to $25^{\circ} \mathrm{C}$. The values vary with the viscosity of the solvents and are slightly different from those found over the range $25^{\circ} \mathrm{C}$ to $80^{\circ} \mathrm{C},{ }^{7}$ because an Arrhenius law does not apply over the whole range $-40^{\circ} \mathrm{C}$ to $80^{\circ} \mathrm{C}$, as it could be for electrolytes in non $\mathrm{H}$-bonded solvents. This energy is considered as the migration energy of ions and reflects mainly the viscous forces of the medium. From these results, as from our previous measurements, we can conclude that Nafion 1100 solutions features are mainly determined by the solvent properties.

Membranes: Membranes conductance measurements have been performed at room temperature during the swelling. Figure 4 shows the thickness and the conductance variations versus time of the Nafion $\mathrm{Li}^{+}$ and $\mathrm{Na}^{+}$membranes swollen in NMF. The thickness varies as soon as the sample is in contact with the solvent. The increase of the thickness with time is rapid initially, reaches a peak and then decreases to a plateau. The wave before the plateau corresponds to a reorganization of the electrode/membrane contact in the plane, the decrease of the thickness can be explained by a softening of the membrane which flows when fully swollen. This fact confirms the anisotropy of the swelling. ${ }^{4}$ Figure 4 also shows the gap between the beginning of the swelling
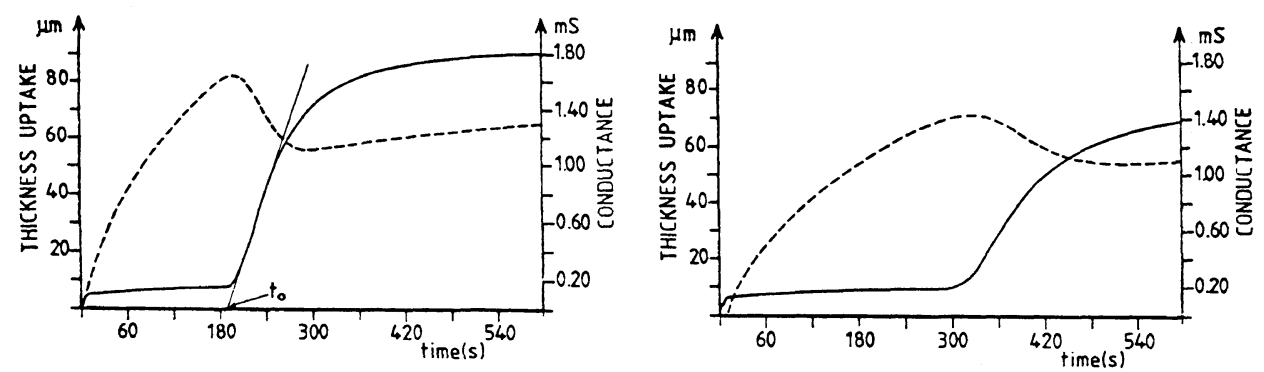

Figure 4. Variations of the conductance (lines) and of the thickness (doted lines) versus time, of a Nafion $\mathrm{Li}^{+}$membrane (on the left) and a Nafion $\mathrm{Na}^{+}$membrane (on the right) swollen in NMF.

and the sudden conduction variation. This phenomenon can be explained as follows: as the swelling begins, only a thin superficial shell of the ion/solvent phase contributes to the conduction, and the value is low. The sudden conduction variation corresponds to two diffusional fronts of the phase in the thickness direction since the swelling is faster in this direction. The conduction then gently reaches a plateau because the swelling continues in the three directions. At longer times, lower swelling rates can cause the conductance decrease due to a 
volume change, e.g. a loss of charges, between the electrodes. The conductance measurements are dependent on the electrode surface quality, while the thickness measurements are not. When analyzing the variation of the conductance with time for a given membrane, figure 4, it is possible to calculate macroscopic diffusion coefficients of cations, $D$, by using the diffusion equation: $x^{2}=8 D t_{0}, \quad x$ being the thickness of the membrane before swelling, and $t_{0}$ the hold-up time. ${ }^{8}$ Table 3 gives the diffusion coefficients of lithium in $\mathrm{H}_{2} \mathrm{O}$, EtOH, NMF and PC swollen membranes. Table 4 gives that of $\mathrm{H}^{+}, \mathrm{Li}^{+}, \mathrm{Na}{ }^{+}, \mathrm{Rb}^{+}$in $\mathrm{H}_{2} \mathrm{O}$ swollen

Table 3. Diffusion coefficient values of lithium in membranes swollen in polar solvents.

\begin{tabular}{|c|c|c|c|c|}
\hline solvent & $\mathrm{H}_{2} \mathrm{O}$ & EtOH & NMF & PC \\
\hline $\begin{array}{c}\text { Lithium diffusion } \\
\text { coefficient } \\
\left(\mathrm{cm}^{2} \cdot \mathrm{s}^{-1}\right)\end{array}$ & $5.4 \cdot 10^{-7}$ & $1.06 \cdot 10^{-7}$ & $6.7 \cdot 10^{-8}$ & $3.7 \cdot 10^{-9}$ \\
\hline
\end{tabular}

Table 4. Diffusion coefficient values of counter-ions for Nafion $\mathrm{H}^{+}, \mathrm{Li}^{+}, \mathrm{Na}^{+}$and $\mathrm{Rb}^{+}$exchanged membranes swollen in water.

\begin{tabular}{|c|c|c|c|c|}
\hline counter-ion & $\mathrm{H}^{+}$ & $\mathrm{Li}^{+}$ & $\mathrm{Na}^{+}$ & $\mathrm{Rb}^{+}$ \\
\hline $\begin{array}{c}\text { diffusion coefficient } \\
\left(\mathrm{cm}^{2} \cdot \mathrm{s}^{-1}\right)\end{array}$ & $1.08 \cdot 10^{-6}$ & $5.4 \cdot 10^{-7}$ & $2.1 \cdot 10^{-7}$ & $7.7 \cdot 10^{-8}$ \\
\hline
\end{tabular}

membranes. It is not surprising that the coefficient decreases with the counter-ions radius and with the DN of the solvent, since large counter-ions are more difficult to solvate and to move. The value $1.08 \cdot 10^{-6} \mathrm{~cm}^{2} . \mathrm{s}^{-1}$, found for the diffusion coefficient of protons in water swollen membranes is very close to $0.83 \cdot 10^{-6} \mathrm{~cm}^{2} \cdot \mathrm{s}^{-1}$ given in the literature for water. ${ }^{9}$ This is an indication of the large water solvation of the protons. Figure 5 and 6 show the influence of the nature of the solvents and that of counter-ion radii on the

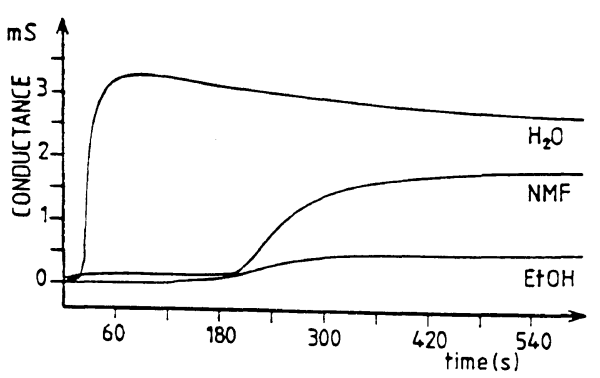

Figure 5. Conductance versus time of Nafion $\mathrm{Li}^{+}$membranes swollen in $\mathrm{H}_{2} \mathrm{O}$, EtOH and NMF.

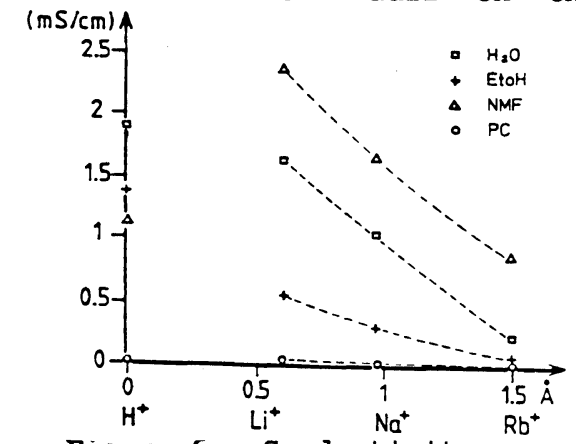

Figure 6. Conductivity versus the ionic radius of counterion of membranes swollen in $\mathrm{H}_{2} \mathrm{O}$, EtOH, NMF and PC. 
conductivity, respectively. The properties of polar solvents (Gutmann donor number $\mathrm{DN}$, and molar volume $\mathrm{V}_{M}$ ), in connection with the thickness increase $\Delta e / e$, and with the conductivity $\sigma$, at the steady state conditions are listed in table 5 for Nafion $\mathrm{H}^{+}$and $\mathrm{Li}^{+}$membranes. The $\Delta \mathrm{e} / \mathrm{e}$ is $\sim 12 \%$ in dioxanne and acetonitrile, $5.7 \%$ in xylene and $4.2 \%$ in

Table 5. Conductivity and values of thickness increases of $175 \mu$ Nafion $\mathrm{H}^{+}$and $\mathrm{Li}^{+}$exchanged membranes in polar solvents.

\begin{tabular}{|c|c|c|c|c|c|c|}
\hline & & & \multicolumn{2}{|c|}{ Nafion $\mathrm{H}^{+}$} & Nafion & on $\mathrm{Li}^{+}$ \\
\hline solvent & $\begin{array}{c}V_{M} \\
\left(\mathrm{~cm}^{3} \cdot \mathrm{mol}^{-1}\right)\end{array}$ & $\begin{array}{c}\mathrm{DN} \\
\left(\mathrm{kcal} \cdot \mathrm{mol}^{-1}\right)\end{array}$ & $\begin{array}{l}\Delta e / e \\
\left(\frac{o}{b}\right)\end{array}$ & $\begin{array}{c}\sigma \\
\left(\mathrm{mS} \cdot \mathrm{cm}^{-1}\right)\end{array}$ & $\begin{array}{l}\Delta e / e \\
\left(\frac{\circ}{6}\right)\end{array}$ & $\begin{array}{c}\sigma \\
\left(\mathrm{mS} . \mathrm{cm}^{-1}\right)\end{array}$ \\
\hline $\mathrm{H}_{2} \mathrm{O}$ & 18.07 & $(18)$ & 5.9 & 1.9 & 12.0 & 2.7 \\
\hline EtOH & 58.7 & $(32)$ & 23.9 & 1.2 & 21.5 & .54 \\
\hline TEP & 170.3 & $(26)$ & 33.8 & 1.0 & - & - \\
\hline NMF & 59.1 & (25) & 20.6 & 1.2 & 27.1 & 1.8 \\
\hline PC & 85.2 & 15.1 & 12.5 & .04 & 18.6 & .06 \\
\hline
\end{tabular}

hexane. The thickness variation is not correlated with the dielectric constant nor with the viscosity of solvents, but firstly related to the donor number, then to the molar volume for solvents with same DN values. Water uptake is weak compare to ethanol, because the water molar volume is very small. On the other hand, because of the high affinity of the counter-ions for water, initial solvation water is not completely removed even after the ionomer has been dryed to $110^{\circ} \mathrm{C}$ under vacuum. An important swelling is observed in TEP. It is probable that this particularly high molar volume solvent solvates ion pairs. Nothing indicates that it could solvate the matrix. On the contrary, in the case of membranes, the conductivity values are not correlated with the swelling, excepted for protonated membranes for which values are decreasing with the solvating power of the solvents. The conductivity of alkali metal Nafion membranes appears to be related to the solvent dielectric constant. Figure 6 shows that the conductivity decreases with the ionic radii of the counter-ions indicating that there is a steric effect on the ion mobility.

A comparison of the conductivity values of gels with that of membranes can be made given that specific conductivities are reported for gels, and that macroscopic dimensions have been used to calculate the constant of the cell in the case of the membranes.

In conclusion, as for classic solutions the solvent parameters govern the conductive properties of gelatinous solutions of Nafion 1100. The conductivity of a $0.25 \mathrm{M}$ solution is $5.10^{4-} \mathrm{Scm}^{-1}$ in $\mathrm{PC}$ and $10^{-3} \mathrm{Scm}^{-1}$ in a 50/50 mixture PC/DME at room temperature and looses only one order of magnitude at $-40^{\circ} \mathrm{C}$. There is no structural change over the range $25^{\circ} \mathrm{C}$ to $-40^{\circ} \mathrm{C}$, as opposed to solid polymer electrolytes for which there is a drastic loss of the conductive properties due to a phase transition at low temperature. ${ }^{10}$ For a given solution of ionomer the mobility of cations are inversely proportionnal to the medium viscosity. This ion /solvent interaction is compatible with the rod like structure of the solutions, where all the ions located at the rod surface are in contact with the solvent. ${ }^{6}$ 
Fast ion/solvent phase diffusion has been found in membranes. The swelling has been related to the donor number and to the molar volume of the solvents. The driving force of the swelling is the affinity of the solvent for the ions. This result is confirmed by Gebel.4 The membrane conductivities also depend on the solvents properties. Nevertheless, the polymer volumic fraction here varies from 50 to $90 \%$ compared to $10-20 \%$ in solutions (it is not possible to solubilize so high proportion of polymer in order to make a direct comparison). Therefore if, in the gels, the matrix can be considered as a passive actor of the conductance, in the membranes, the elastic forces of the matrix have to balance the swelling of the ionic part of the polymer. ${ }^{4}$

\section{ACKNOWLEDGEMENTS}

We are very grateful to Mr M. Brotte for his technical help, and to Mr C. Le Bouffant for conductance measurements. The low temperature conductivity measurements have been made possible by the financial support of the "Direction des Recherches - Etudes et Techniques" (contrat $n^{\circ} 89 / 1193$ ).

\section{REFERENCES}

1 W.G. Grot, and F. Chadds, European Patent 066369 (1982).

2 C.R. Martin, T.A. Rhoades, and J.A. Fergusson, Anal. Chem., 54, 1639 (1982).

3 P. Aldebert, and M. Pineri, French Patent 8605792 (1986).

4 G. Gebel, Thèse, Grenoble (1989).

5 A. Eisenberg, and H.L. Yeager, Ed "Perfluorinated Ionomer Membranes", ACS Symposium Series No 180, Washington DC, 1982, p. 217 .

6 P. Aldebert, B. Dreyfus, G. Gebel, N. Nakamura, M. Pineri, and F. Volino, J. Phys. France, 49, 83 (1988).

7 M. Guglielmi, P. Aldebert, and M. Pineri, J. of Applied Electrochem., 19, 167-173 (1989).

8 F. Helfferich, "Ion Exchange", McGraw-Hill, New York, 1962.

9 F. Volino, and M. Pineri, J. of Polymer Science: Polymer Physics, 20, 481 (1982).

10 J.R. Mac Callum, and C.A. Vincent, "Polymer Electrolytes Reviews", Elsevier, Barking, 1987, vol. 1. 